\title{
Consideraciones políticas y económicas relevantes en el 2020 para el fortalecimiento de la enfermería de salud mental española
}

\author{
Relevant political and economic considerations in 2020 for the strengthening
} of the Spanish mental health nursing

\section{Carlos Aguilera Serrano}

Secretario de la Asociación Española de Enfermería de Salud Mental (AEESME)

Fecha de recepción: 12 de diciembre de 2019 / Fecha de aceptación: 18 de diciembre de 2019

Es manifiesto el impacto de los problemas de salud mental en las personas y sus familias, en las distintas comunidades que configuran el tejido social y en la sociedad en su conjunto. Los problemas sociales asociados con las enfermedades mentales incluyen, entre otros, la pobreza, el desempleo o la reducción de la productividad, la migración o la falta de vivienda, constituyéndose como hechos y/o circunstancias que influyen en la experiencia de las personas que sufren estos problemas, promoviendo su aislamiento, discriminación y estigma.

Además, en España, según el último informe publicado de la OCDE, los costes totales asociados a los problemas de salud mental son de 45058 millones de euros (4,17\% del PIB), de los cuales 14415 millones de euros (1,33\% del PIB) y 12318 millones de euros (1,14\% del PIB), son costes directos en Sistemas de Salud y en programas de seguridad social, respectivamente'.

El 11 de diciembre de 2006, el Gobierno de España aprobó la "Estrategia en Salud Mental del Sistema Nacional de Salud", llevando hoy día más de 6 años en desuso. Esta se constituyó como un texto de apoyo para la coordinación efectiva en todo el país de los distintos planes o programas de promoción de la salud mental, de los programas de prevención y de los medios de diagnóstico, terapéuticos y rehabilitadores apropiados para realizar una atención integral y continuada de las personas que presentan problemas de salud mental. Igualmente, la estrategia incluía entre sus objetivos la potenciación de la investigación en salud mental así como la creación de herramientas que permitieran evaluar el avance del conocimiento en este campo ${ }^{2}$.

El modus operandi gubernamental nos lleva a ratificar el incumplimiento del compromiso firmado en la Asamblea Mundial de la Salud en 2012, donde se aprobó, junto con el resto de los Estados miembros, el Plan de acción integral sobre salud mental 2013-2020³ ; pero además, y al igual que pasa en la mayor parte del mundo, ni remotamente se le atribuye al ámbito de la salud mental la misma importancia que lo que tiene que ver con el ámbito de la salud física, si así pudiésemos dividir aspectos íntimos de la atención integral de las personas; esto pone en evidencia el abandono e indiferencia general que se tiene hacia la salud mental.

Contrarrestando, y como parte del esfuerzo pendiente para implementar las recomendaciones de los distintos informes y directrices mundiales en materia de salud mental, las comunidades autónomas del Estado español han ido actualizando sus programas y estrategias destinadas a mejorar la salud mental de la población.

Existe cierta propensión en el sistema sanitario a intentar permanentemente adecuarse en sus estructuras y formas de funcionamiento a una sociedad cambiante y cada vez más exigente. Esto favorece los enfoques colaborativos interdisciplinarios, la participación cada vez mayor de los pacientes en las decisiones clínicas sobre su salud y en las decisiones relativas a la propia gestión de las instituciones, al desarrollo y utilización de las nuevas tecnologías. Este nuevo rumbo en la atención requerida para proporcionar y, sobre todo, obtener buenos resultados en términos de salud, exige evitar ciertos rígidos límites en la acción de los y las profesionales, reconociendo a su vez el valor de la atención integral en la que concomitan distintos perfiles. 
Esta implacable acción profesional requiere de un mayor virtuosismo aún, si cabe, en el inesperado y nuevo escenario social, sanitario y político producto de la grave crisis de salud pública a causa de la pandemia ocasionada por el coronavirus (COVID-19), donde el impacto de los cuidados por parte de las enfermeras especialistas en salud mental con las personas y familias infectas, pero también con los sobrevivientes y los propios trabajadores de la salud, se torna crucial en la reducción de la carga del sufrimiento humano.

El año 2020 debe ser el año en el que se geste un entorno político y económico comprometido con una atención y cuidado en salud mental de alta calidad, responsable y rentable para examinar el producto enfermero.

La enfermería de salud mental, como disciplina que brinda servicios, necesitará establecer firmemente su identidad, contribución colaborativa y su impacto positivo y rentable para ser tomada en serio en su determinación como fuerza laboral en salud mental.

Rosamaría Alberdi (2019), en su abordaje sobre la competencia política enfermera, hacía referencia a esa imprescindible participación y acción política del colectivo, sirviendo de factor facilitador para dar respuesta a las nuevas necesidades de cuidados y cumplir también con la obligación de contribuir a la lucha contra las desigualdades aportando la perspectiva del cuidado ${ }^{4}$.

La argumentación para poder apoyar el liderazgo y potencial de la enfermería de salud mental como fuerza laboral significativa deberá estar regida por la evidencia. Si bien se reconoce que no todo lo que hacen las enfermeras como especialistas en salud mental es cuantificable, y que gran parte del arte de su práctica desafía la medición, es importante considerar si lo que se hace es efectivo para los usuarios del servicio en su camino hacia la recuperación. Evaluar la acción enfermera es importante para la supervivencia de la misma como profesión, pero, sobre todo, es importante para garantizar que los cuidados enfermeros sean eficaces para los usuarios de los servicios y sus familias.

Reconocer en pleno siglo XXI que las enfermeras especialistas en salud mental de España son una fuerza laboral establecida en el cuidado de la salud mental conlleva implícitamente la responsabilidad de continuar articulando y ejecutando claramente su contribución.

\section{Bibliografía}

1. OECD/EU. Health at a Glance: Europe 2018: State of Health in the EU Cycle. Paris: OECD Publishing. 2018. Available from: https://doi.org/10.1787/health_glance_eur-2018-en

2. Ministerio de Sanidad y Consumo. Estrategia en Salud Mental del Sistema Nacional de Salud, 2006. [Internet]. Madrid; 2007. Available from www.mscbs.gob.es/organizacion/sns/planCalidadSNS/pdf/excelencia/salud_mental/ESTRATEGIA_SALUD_MENTAL_SNS_PAG_WEB.pdf

3. OMS. Plan de acción sobre salud mental 2013-2020. [Internet]. Ginebra; 2013. Available from: https://apps.who.int/iris/bitstream/handle/10665/97488/9789243506029_spa.pdf?sequence=1

4. Alberdi Castell RM. La competencia política enfermera. Contexto, conceptualización y ámbitos de desarrollo. Rev Rol Enferm. 2019; 42(1):22-30. 